\title{
Assessment of a fragment of e-cadherin as a serum biomarker with predictive value for prostate cancer
}

\author{
R Kuefer ${ }^{*, 1,2}$, MD Hofer ${ }^{1,3}$, CSM Zorn ${ }^{1,2}$, O Engel', BG Volkmer', MA Juarez-Brito', M Eggel', JE Gschwend', \\ MA Rubin ${ }^{3,4}$ and ML Day ${ }^{2,4}$ \\ 'Department of Urology, Faculty of Medicine, University of Ulm, Prittwitzstrasse 43, Ulm 89075, Germany; ${ }^{2}$ Department of Urology and the O'Brien \\ Cancer Center, University of Michigan, Ann Arbor, MI 48109, USA; ${ }^{3}$ Department of Pathology, Brigham and Women's Hospital, Harvard University, \\ School of Medicine, Boston, MA 2500, USA
}

In prostate cancer, biomarkers may provide additional value above standard clinical and pathology parameters to predict outcome after specific therapy. The purpose of this study is to evaluate an $80 \mathrm{kDa}$ fragment of the cell adhesion molecule e-cadherin as a serum biomarker. A broad spectrum of prostate cancer serum samples, representing different stages of prostate cancer disease, including benign prostatic hyperplasia (BPH), localised (Loc PCA) and metastatic prostate cancer (Met PCA), was examined for the cleaved product. There is a significant difference in the expression level of the $80 \mathrm{kDa}$ fragment in the serum of healthy individuals vs patients with $\mathrm{BPH}$ and between BPH vs Loc PCA and Met PCA $(P<0.00 \mathrm{I})$. Highest expression levels are observed in advanced metastatic disease. In the cohort of Loc PCA cases, there was no association between the $80 \mathrm{kDa}$ serum concentration and clinical parameters. Interestingly, patients with an $80 \mathrm{kDa}$ level of $>7.9 \mu \mathrm{g} \mathrm{I}^{-1}$ at the time of diagnosis have a 55-fold higher risk of biochemical failure after surgery compared to those with lower levels. This is the first report of the application of an $80 \mathrm{kDa}$ fragment of e-cadherin as a serum biomarker in a broad spectrum of prostate cancer cases. At an optimised cutoff, high expression at the time of diagnosis is associated with a significantly increased risk of biochemical failure, potentially supporting its use for a tailored follow-up protocol for those patients. British Journal of Cancer (2005) 92, 2018 -2023. doi:I0.1038/sj.bjc.6602599 www.bjcancer.com

Published online 3 May 2005

(c) 2005 Cancer Research UK

Keywords: e-cadherin; human prostate cancer; serum biomarker; $80 \mathrm{kDa}$ fragment; progression

Prostate-specific antigen (PSA) screening has revolutionised early detection of prostate cancer. Still, prostate cancer is a leading cause of male cancer-related deaths in the western world. Men with clinically localised prostate cancer have excellent chances for long-term cure. However, treatment options are rare in advanced disease stage or in case of failure after specific therapy. Therefore, it is crucial to identify the potentially progressing prostate cancer at its earliest stage. One way to evaluate patient risk is to use standard nomograms, which take clinical and pathology parameters into account. Nomograms have been developed, for example, for predicting the 5-year probability of treatment failure among men with clinically localised prostate cancer treated with radical prostatectomy (Kattan et al, 1998), and the probability of successful treatment 5 years after brachytherapy for clinically localised prostate cancer (Kattan et al, 2001). Ideally, nomograms would help clinicians to identify progressing tumours after specific therapy, indicating early adjuvant therapeutic means or at least supporting a more tailored follow-up regimen. There appears to be significant opportunity to identify biomarkers to strengthen currently available nomograms by providing information with

*Correspondence: Dr R Kuefer; E-mail: rainer.kuefer@medizin.uni-ulm.de ${ }^{4}$ These authors contributed equally to this work

Received 9 December 2004; revised 15 March 2005; accepted 24 March 2005; published online 3 May 2005 respect to tumour biology at the time of diagnosis (Potter et al, 2001).

The $120 \mathrm{kDa}$ full-length e-cadherin is known to be important for well-functioning cell-cell adhesion and its cleavage has been linked to the malignant progression of adenocarcinomas including prostate cancer (Giroldi and Schalken, 1993; Rios-Doria et al, 2002). In a recent study, an $80 \mathrm{kDa}$ fragment of full-length e-cadherin has been described as almost exclusively being observed in the neoplastic aspect of prostate cancer tissue (Kuefer et al, 2003). This soluble fragment has also been reported as being measurable in the serum of patients suffering from different types of adenocarcinoma (Katayama et al, 1994a; Banks et al, 1995; Gofuku et al, 1998; Velikova et al, 1998; Protheroe et al, 1999; Chan et al, 2003). In the current study, we report the accumulation of this $80 \mathrm{kDa}$ fragment of e-cadherin in the serum of patients affected by prostate cancer. Its potential use as a serum marker with predictive value for prostate cancer progression is elucidated.

\section{MATERIALS AND METHODS}

\section{Sample collection}

Serum samples were taken from the radical prostatectomy series and from the Rapid Autopsy Program at the University of Michigan. The serum was collected as a standard procedure of all individuals undergoing surgery. In order to study hormone 
refractory prostate cancer, a Rapid Autopsy Protocol was developed. As a routine procedure, blood is taken from these patients with far advanced disease on a regular basis till the time of autopsy. Of all patients, blood samples were taken and immediately processed and stored at $-80^{\circ} \mathrm{C}$. Clinical and pathology data for all patients was acquired with approval from the Institutional Review Board (IRB) at the University of Michigan and maintained on a secure relational database.

In this retrospective setting, serum samples were grouped according to following clinical categories in order to examine the widest range of prostate cancer disease: one group consisted of 13 healthy young volunteers. The second group was represented by 29 patients with benign prostatic hyperplasia (BPH). The third group consisted of 109 patients with localised prostate cancer (Loc PCA). Of these patients, serum at the time of diagnosis was available and none of these patients failed during follow-up after radical prostatectomy. The fourth group included 21 cases with localised PCA and biochemical failure after surgery during follow-up. The last cohort consisted of 16 serum samples of different patients with generalised metastatic disease (Met PCA). Detailed clinical data of all patients are given in Table 1.
In this study, Loc PCA is defined as all tumour stages according to the current TNM classification (T1-T4). Patients with nodepositive disease were not included due to the small number of cases. Also, patients with other malignancies besides PCA or chronic inflammatory diseases (Katayama et al, 1994a) were excluded. None of the patients had neoadjuvant therapy and none of the patients with localised PCA received other cancer-specific treatment besides radical prostatectomy.

\section{Serum analysis of the $80 \mathrm{kDa}$ e-cadherin fragment}

Serum concentrations of the $80 \mathrm{kDa}$ fragment were analysed using the Human E-cadherin EIA Kit from Zymed Laboratories, San Francisco, USA. In this commercially available kit, HECD-1 is the e-cadherin-specific antibody. HECD-1 is highly specific and known to map to the extracellular domain of e-cadherin, where the $80 \mathrm{kDa}$ fragment derives from (Kuefer et al, 2003). In the serum, the soluble $80 \mathrm{kDa}$ is the only cleaved product being seen by the HECD-1 antibody. As first step, a standard curve was created using the suppliers lyophilised human e-cadherin. To this standard curve, a curve was fitted to

Table I Demographics of all patients who were evaluated for the expression of the $80 \mathrm{kDa}$ fragment of e-cadherin in the serum

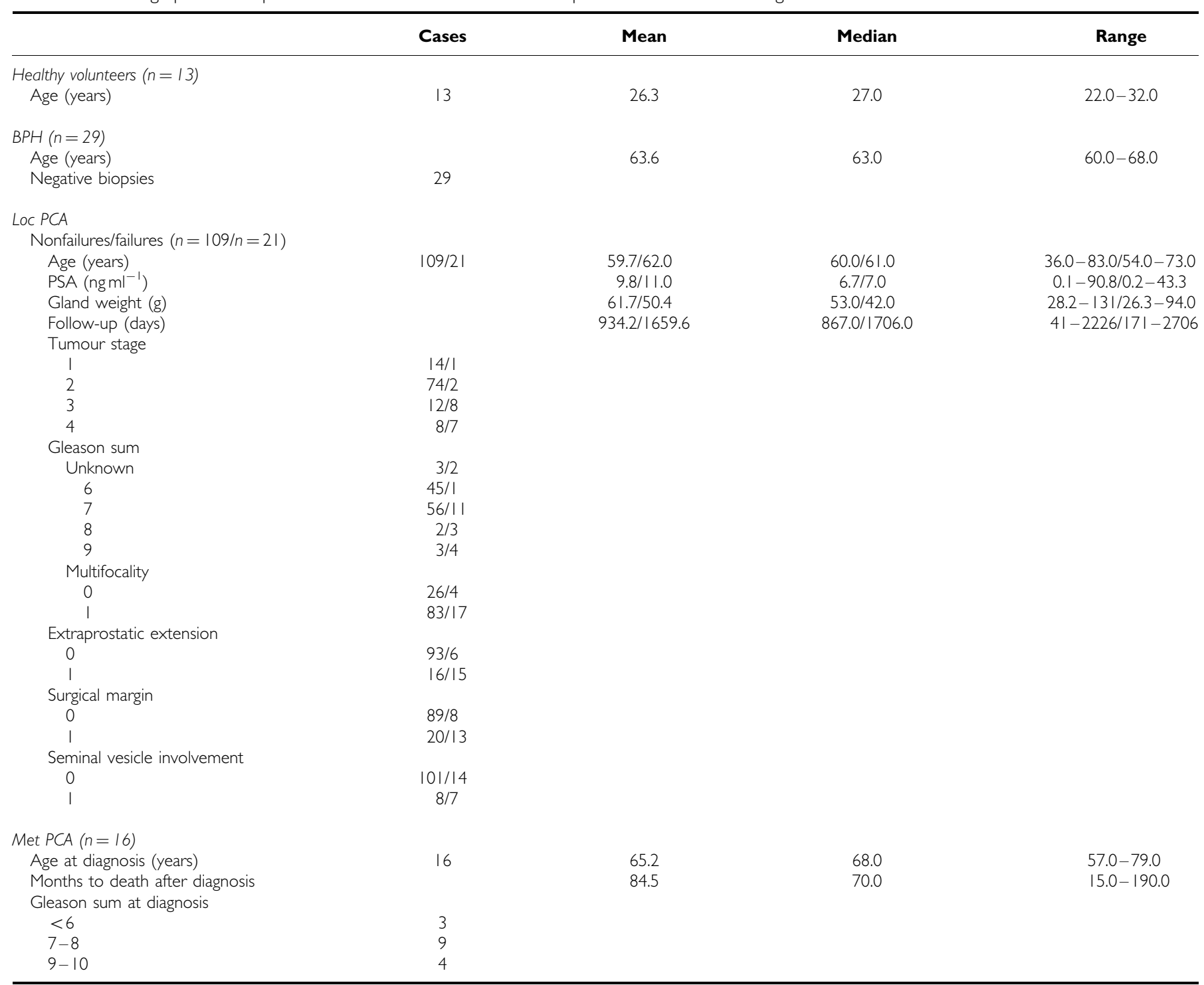

$\mathrm{BPH}=$ benign prostatic hyperplasia; $\mathrm{Loc}$ PCA = localised prostate cancer; Met PCA = metastatic prostate cancer; PSA = prostate-specific antigen. 
convert the detected optical densities (OD) into $80 \mathrm{kDa}$ concentrations of the individual serum samples. In this setting, a cubic model with the formula $(1.1305 \times \mathrm{OD})+\left(-0.6712 \times \mathrm{OD}^{2}\right)$ $+\left(0.1624 \times \mathrm{OD}^{3}\right)$ was the optimal model to fit the standards $(\mathrm{RSQ}=0.981)$.

Measurements of samples with an $\mathrm{OD} \geqslant 3.0$ were repeated using higher dilutions. The kit was tested for low intrasample and interplate variability. A representative set of samples was also tested in a time-course experiment to rule out an association between time till the samples were processed and the amount of the cleaved e-cadherin fragment.

Absorbance was measured at $450 \mathrm{~nm}$ using a standard 96-well microtiter plate reader. Measurement was carried out in triplicate for each sample and the mean value was used for statistical analysis.

\section{Statistical analyses}

The OD values were imported into SPSS (SPSS, Chicago, USA) and transformed into $80 \mathrm{kDa}$ serum concentrations according to the above formula for statistical analysis. The expression levels of the $80 \mathrm{kDa}$ serum fragment were evaluated for all serum samples (i.e. healthy volunteers, BPH, Loc PCA, Met PCA) and are graphically presented as error bars with $95 \%$ confidence intervals (CI). A comparison of expression levels between different cohorts (i.e. BPH vs Loc PCA) was performed using the Mann-Whitney test, or the Wilcoxon's signed-rank test for dependent samples. For the Loc PCA samples, the $80 \mathrm{kDa}$ serum expression was investigated for association with clinical and pathological parameters (e.g. tumour stage) using Cramer's V for categorised values. Cramer's V represents a correlation coefficient; the lower (towards 0 ) the less correlation is given and the higher the value (towards 1), the more correlation is present. Kaplan-Meier analysis was performed to estimate survival. As surrogate end point for survival, biochemical recurrence during follow-up was chosen, being defined as two consecutive PSA rises after a nadir of undetectable PSA after surgery. Univariate, unmatched comparisons of survival were carried out using the log-rank test. The Wald test was used for Cox's hazards regression analysis applying a backward stepwise elimination of variables in multivariate models. Risk ratios (relative hazards) were calculated based on the Cox model and are presented with $95 \%$ CI. Values of $P<0.05$ were considered significant.

\section{RESULTS}

\section{Expression of the $80 \mathrm{kDa}$ fragment for different clinical categories}

The serum levels of healthy volunteers $(n=13)$ was compared to patients with BPH $(n=29)$ and patients with Loc PCA $(n=130)$ and those with Met PCA $(n=16)$. Healthy volunteers, BPH, Loc PCA and Met PCA had a mean $80 \mathrm{kDa}$ concentration of 6.27 (standard error (s.e.) $0.31,95 \%$ CI 5.59-6.96), 7.26 (s.e. 0.21, CI 6.82-7.70), 9.46 (s.e. 0.42, CI $8.63-10.29$ ) and 27.49 (s.e. 4.81, CI $17.23-37.75)$, respectively. Pairwise comparison revealed a statistically significant difference between the serum concentration of the healthy volunteers and the patients with BPH (Mann - Whitney; $P=0.023$ ) and between patients with BPH and Loc PCA (MannWhitney; $P=0.011$ ). Interestingly, there was a highly significant difference between the Loc PCA cases and the serum levels of the patients with metastatic disease $(P<0.001)$. The mean $80 \mathrm{kDa}$ protein expression level for each category is presented in Figure 1, demonstrating a cascade from healthy volunteers $<\mathrm{BPH}<\mathrm{Loc}$ PCA $<$ Met PCA.

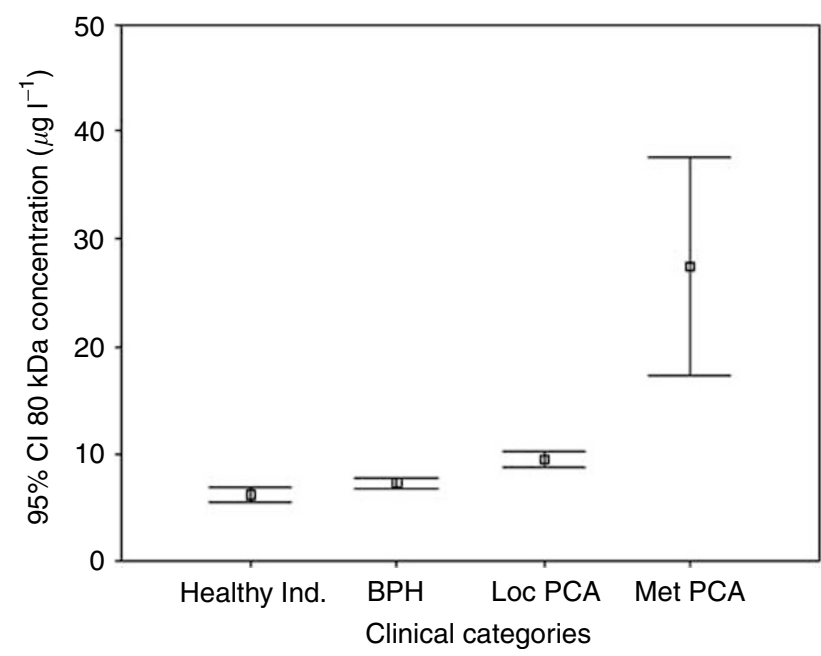

Figure I Detection of the $80 \mathrm{kDa}$ fragment of e-cadherin in the serum of Healthy Individuals (Healthy Ind.), patients with benign prostatic hyperplasia (BPH), patients with localised prostate cancer (loc PCA) and with metastatic disease (Met PCA). Mean concentrations including the 95\% confidence interval $(\mathrm{Cl})$ are given.

\section{Expression of the $80 \mathrm{kDa}$ fragment for patients with Loc PCA}

Association of the $80 \mathrm{kDa}$ expression with clinical and pathological parameters As the $80 \mathrm{kDa}$ fragment has been found to be associated with aggressive clinical course in bladder, gastric and colorectal cancer (Griffiths et al, 1996; Gofuku et al, 1998; Velikova et al, 1998), we looked for potential associations between clinical or pathological parameters in prostate cancer. Two statistical approaches were tested: first step was to create four categories of the $80 \mathrm{kDa}$ serum concentration according to the calculated quartiles; second step was to categorise using the median of the $80 \mathrm{kDa}$ concentration of the cohort of Loc PCA patients. These categories of the serum biomarker were compared to the categorised clinical and pathological parameters. There was no association between expression of the e-cadherin fragment in the serum and any of the following parameters: age, race, preoperative PSA, tumour stage, Gleason score (categorised Gleason sum $<7 ; 7 ;>7$ ), multifocality, seminal vesicle involvement, surgical margin, extraprostatic extension and weight of prostate gland (Cramer's V; values ranged from 0.18 to 0.29 )

Comparison of the $80 \mathrm{kDa}$ serum level at the time of diagnosis and at the time of PSA nadir after radical prostatectomy For this analysis, serum at the time of diagnosis and at the time of nadir after surgery was available of 21 patients (matched pairs). The mean $80 \mathrm{kDa}$ concentration at the time of diagnosis was 8.27 (s.e. $0.68,95 \%$ CI $6.38-9.54$ ) and 7.32 (s.e. 0.88, CI 5.22-9.13) during follow-up. The difference was statistically not significant (Wilcoxon test; $P=0.28$ ).

Comparison of the $80 \mathrm{kDa}$ serum expression at the time of diagnosis and at the time of failure during follow-up For this analysis, serum at the time of diagnosis and at the time of failure was available of seven patients (matched pairs) out of 21 patients who failed. The mean $80 \mathrm{kDa}$ concentration at the time of diagnosis was 8.33 (s.e. $0.69,95 \%$ CI $6.65-10.01$ ) and 7.57 (s.e. 0.87, CI 5.449.73 ) at the time of failure. Statistically there was no significant difference in expression levels (Wilcoxon test; $P=0.31$ ). 
Table 2 Clinical parameters and the concentration of the $80 \mathrm{kDa}$ serum fragment are tested in an univariate and a multivariate regression model for association with outcome

\begin{tabular}{lccc}
\hline Variable & P-value & Hazard ratio & $\mathbf{9 5 \% ~ C l}$ \\
\hline Univariate Cox's proportional-hazard model & & \\
Race & 0.49 & 1.16 & $(0.76-1.79)$ \\
Age (years) & 0.23 & 1.03 & $(0.78-2.14)$ \\
Preoperative PSA $\left(\mathrm{ng} \mathrm{ml}^{-1}\right.$ ) & 0.83 & 1.004 & $(0.97-1.05)$ \\
Gland weight (g) & 0.17 & 0.98 & $(0.95-1.0)$ \\
Gleason sum & $<0.00$ I & 2.49 & $(1.62-3.84)$ \\
Multifocality & 0.67 & 1.27 & $(0.43-3.78)$ \\
Extraprostatic extension & $<0.00$ I & 10.94 & $(4.22-28.37)$ \\
Seminal vesicle involvement & 0.002 & 4.34 & $(1.74-10.81)$ \\
Surgical margin & 0.001 & 4.66 & $(1.91-11.36)$ \\
Tumour stage & $<0.001$ & 2.67 & $(1.69-4.22)$ \\
80 kDa e-cadherin fragment & 0.79 & 1.12 & $(0.45-2.65)$ \\
& & & \\
Multivariate (backward stepwise; Wald) & 0.007 & 2.16 & $(1.24-4.25)$ \\
Gleason sum & 0.007 & 5.34 & $(1.60-17.84)$ \\
Extraprostatic extension & &
\end{tabular}

$95 \% \mathrm{Cl}=95 \%$ confidence interval; PSA = prostate-specific antigen.

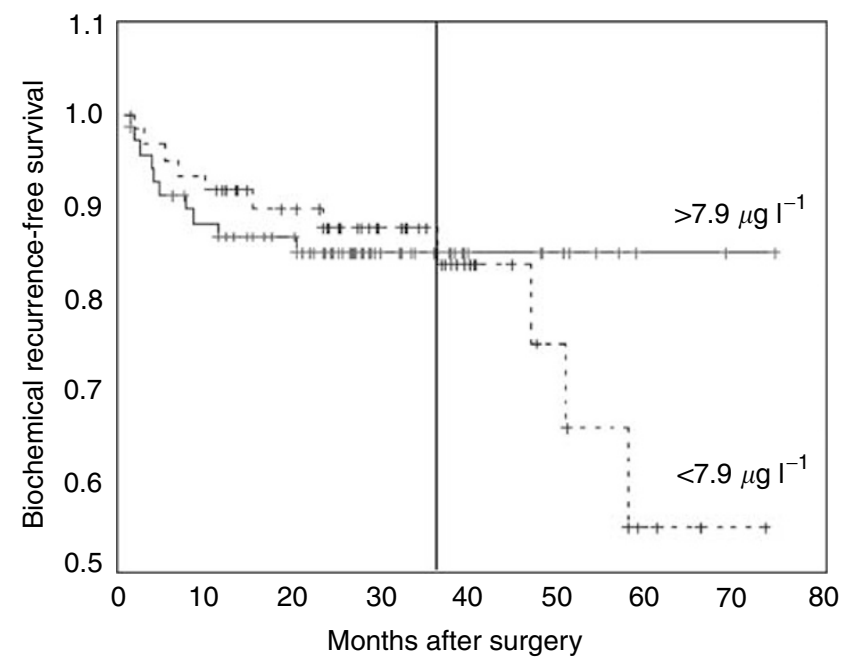

Figure 2 Association of the soluble $80 \mathrm{kDa}$ fragment (cutoff expression level $7.9 \mu \mathrm{gl}^{-1}$ ) at the time of diagnosis of prostate cancer and biochemical failure after radical prostatectomy. Patients with localised disease and with high expression levels prior to surgery have a significantly increased risk of late biochemical failure (after 3 years) during follow-up.

Outcome analysis for the $80 \mathrm{kDa}$ serum expression level in the Loc PCA group $(\mathrm{n}=130)$ The median postsurgery follow-up time was 920.5 days (41-2706 days). The average time to failure was 435.3 days (s.e. 115.5 days). Clinical parameters and the $80 \mathrm{kDa}$ fragment as a serum biomarker were evaluated for their ability to predict outcome. For statistical analysis, a cutoff for the $80 \mathrm{kDa}$ serum level was set at the calculated median of $7.93 \mu \mathrm{gl}^{-1}$ (mean $9.46 \mu \mathrm{gl}^{-1}$; s.e. 0.42 ; CI $8.63-10.29$ ). Tumour stage, Gleason sum (categorised $<7 ; 7 ;>7$ ), extraprostatic extension, seminal vesicle involvement and surgical margin showed a strong association with outcome (log rank; $P<0.002$ ). Preoperative PSA, age, multifocality of the prostate cancer and race did not show an association with outcome (log rank; $P>0.2$ ). In the multivariate Cox regression analysis, applying a backward model selection for all the given parameters, Gleason sum and extraprostatic extension of the cancer had the best model performance (log rank; $P=0.007$ ). Detailed data of the
Cox proportional-hazard model for all the clinical parameters including confidence intervals is given in Table 2. As in the case of the $80 \mathrm{kDa}$ e-cadherin fragment, at first glance there was no association between the serum level and PSA failure (log rank; $P=0.79,95 \%$ CI $0.48-2.65)$. Interestingly, when performing a subanalysis, starting at a follow-up time of 35 months, the $80 \mathrm{kDa}$ level was associated with outcome (log rank; $P<0.05)$. In this model, the relative risk for PSA failure was 55.1 (s.e. 4.14). The association between the $80 \mathrm{kDa}$ expression and clinical failure is presented graphically in a Kaplan-Meier curve demonstrating a significantly higher risk of PSA failure for patients with $80 \mathrm{kDa}$ serum levels $>7.9 \mu \mathrm{gl}^{-1}$ once a follow-up time of 3 years has passed (Figure 2).

\section{DISCUSSION}

Without doubt, PSA is one of the best tumour markers in oncology. It was first identified by Hara et al in 1971 in seminal plasma and some years later in prostate tissue (Wang et al, 1979). In the last 20 years screening, treatment approaches and follow-up for prostate cancer have been dramatically influenced by the widespread usage of PSA. Owing to the high prevalence of prostate cancer, tumour marker research still is particularly challenging as PSA is known to have some limitations in its application especially in the diagnostic window of $4-10 \mathrm{ng} \mathrm{ml}^{-1}$ (Partin et al, 1990). In fact, in combination with other clinical parameters PSA helps to predict locally advanced or metastatic disease (Sands et al, 1994; Partin et al, 1997; Cagiannos et al, 2003), whereas limited information is available to predict failure after specific therapy, possibly guiding high-risk patients into tailored follow-up protocols (Pound et al, 1999; Kattan et al, 2001). In the presented study, we ought to analyse a soluble fragment of e-cadherin for its potential use as a serum biomarker in prostate cancer disease.

E-cadherin is a cell adhesion molecule playing a major role in maintaining proper epithelial cell-to-cell structure (Takeichi, 1990). This member of the cadherins, also called uvomorulin, is a $120 \mathrm{kDa}$ transmembrane gylcoprotein. A very early report about the association between altered cell adhesion and tumour progression was published by a pathologist almost 60 years ago (Coman, 1944). After 40 years, reports of e-cadherin cleavage emerged when Wheelock and Damsky presented the discovery of a $80 \mathrm{kDa}$ species of e-cadherin based on cell culture experiments (Wheelock et al, 1987). This proteolytic fragment, detectable in the media of tumour cells, was derived from the amino-terminal end of e-cadherin and could be reproducibly generated by a series of stress stimuli such as starving or high calcium loading. This fragment was thought to act proinvasive due to its ability to disrupt the cell - cell adhesion of mammary epithelium (Wheelock et al, 1987; Noe et al, 2001). In several previous studies including our own, decreased e-cadherin expression either alone or in combination with other biomarkers has been described as being associated with prostate cancer progression (Umbas et al, 1992; Takeichi, 1993; Rubin et al, 2001; Rhodes et al, 2003). We also reported that increased cleavage of the full-length $120 \mathrm{kDa}$ ecadherin, leading to 97 and $100 \mathrm{kDa}$ fragments, was observed in neoplastic prostate tissue (Rashid et al, 2001; Rios-Doria et al, 2002). In a recent study, a considerable accumulation of the $80 \mathrm{kDa}$ fragment in the extracellular compartment of metastatic prostate tissue has been observed (Kuefer et al, 2003). Several potential mechanisms have been discussed in the literature for being responsible for the shedding of e-cadherin (Takeichi, 1988; Katayama et al, 1994b; Banks et al, 1995; Noe et al, 2001; Ryniers et al, 2002). Still, the underlying pathomechanics need further investigation as the cleaved product of e-cadherin represents most likely only a bystander effect. Once these mechanisms, which lead to the cleaved product, are identified, specific therapy might be 
initiated with the potential use of the e-cadherin fragment as a marker for successful therapy.

Several studies, all using HECD-1 as the primary antibody for detection of the $80 \mathrm{kDa}$ fragment, have reported the presence of the $80 \mathrm{kDA}$ fragment in the serum of patients suffering from intestinal or bladder cancer.

The amount of detectable soluble $80 \mathrm{kDa}$ e-cadherin was significantly higher in patients with gastric cancer compared to healthy individuals (Katayama et al, 1994a; Gofuku et al, 1998; Chan et al, 2001). Indeed, the $80 \mathrm{kDa}$ serum levels were more sensitive for malignancies than well-known tumour markers, the carcinoembryonic antigen and CA19-9, a ligand of E-selectin (Gofuku et al, 1998). In a very recent study, the serum concentrations were an independent predictive factor for longterm survival in patients with gastric cancer (Chan et al, 2003). This observation and the fact that the expression levels did not correlate to clinical parameters such as T-stage is in accordance with the results described in this study. In contrast to our findings, for gastric cancer, a quick decline within already 7 days after surgery was observed (Gofuku et al, 1998). It was stated that a high concentration in gastric cancer patients predicted palliative treatment as there was a strong association to metastatic disease (Chan et al, 2001). Although colon cancer is an intestinal neoplasia as well, Velikova et al (1998) could not confirm these findings for colon cancer.

The soluble $80 \mathrm{kDa}$ fragment was not only measured in the serum but also in the urine of patients. In one study, it was assumed that the $80 \mathrm{kDa}$ fragment is excreted into the urine as increased levels could be measured among patients with different primaries (Katayama et al, 1994a). In bladder cancer, Banks et al described the existence of soluble forms of e-cadherin in the urine. An enhanced shedding and thus increased fraction of e-cadherin fragments was discussed as a loss of e-cadherin function in malignant changes of the bladder (Banks et al, 1995). This observation was put in perspective to the fact that decreased e-cadherin expression has been shown to be associated with poor survival in bladder cancer patients (Bringuier et al, 1993; Syrigos et al, 1995). In a more recent study, the soluble e-cadherin was included in a protein/creatinine index. This index showed a significant difference between invasive and noninvasive bladder cancers. Still, it was concluded that this protein alone most likely will not be useful for bladder cancer screening (Protheroe et al, 1999). Another study investigated the serum expression at the time of presentation and found significantly higher expression levels in patients with high-grade and muscle invasive bladder tumours. The most interesting finding for bladder cancer, which is in accordance with the presented results for prostate cancer, was the fact that patients at risk of early relapse of superficial bladder tumours had significantly elevated serum levels of soluble ecadherin at presentation (Griffiths et al, 1996).

In this study, we demonstrated in a broad spectrum of prostate cancer disease stages and in comparison to healthy individuals and benign hyperplasia of the prostate, a very strong association of the $80 \mathrm{kDa}$ fragment in the serum with neoplastic changes of the gland. The highest expression levels are seen in patients with advanced hormone refractory metastatic prostate cancer. The $80 \mathrm{kDa}$ fragment in this setting was independent of any clinical parameters, including those related to tumour burden, in the cohort of clinically localised PCA cases. This observation is surprising, but may suggest that the $80 \mathrm{kDa}$ e-cadherin fragment reflects biological character of the underlying cancer. The tumour biology obviously could be directly related to metastatic potential and thus to late recurrence after specific therapy. This hypothesis may explain the fact that in this setting patients with Loc PCA and a high $80 \mathrm{kDa}$ serum level at the time of diagnosis have a considerable high risk of biochemical failure after surgery starting at a follow-up time of 3 years. To gain further insight into the underlying pathomechanics and to understand better why there is no association with tumour burden, a matched pairs analysis of serum levels of the fragment and e-cadherin expression in tissue samples might be helpful (Griffiths et al, 1996). Although further work is needed, these observations, in conjunction with the high serum expression levels in patients with far advanced lethal PCA, make the authors believe that the $80 \mathrm{kDa}$ expression level has the potential to serve as biomarker with predictive value. As stated above, a real value for the urologist most likely could be its application in conjunction with other well-described parameters after cancer-specific therapy. It also would be very important to test lymph node-positive prostate cancer patients for their $80 \mathrm{kDa}$ serum levels as these patients are more likely to fail during follow-up and therefore would benefit most from a biomarker with predictive value. Although this study refers to a decent sample size, a limitation is the low number of events $(n=21)$, which may explain why PSA was not a predictor of failure in the cohort of localised PCA cases in this setting and which results in a limited degree of freedom in regression models. Consecutively, this serum marker needs to be approved in a larger and ideally prospective setting. Based on valid clinical interpretation, it may then help to tailor the follow-up regimen in patients being at high risk of failure. In upcoming studies, the end point preferably should not be biochemical failure, as an association to clinical recurrence or disease-specific death is most important and needs to be demonstrated. As there was no change in the serum levels between time of diagnosis and serum levels after surgery, the $80 \mathrm{kDa}$ fragment may also serve as a marker for patients undergoing other therapeutic means for localised PCA.

The management of a patient with prostate cancer requires that prognostic information is available for defining an optimised treatment plan. The presented results are promising that the $80 \mathrm{kDa}$ fragment of e-cadherin can be approved as a serum biomarker for prostate cancer, being detectable at early stages of disease before specific therapy is initiated and potentially providing additional prognostic information besides clinical and pathological data.

\section{ACKNOWLEDGEMENTS}

Special thanks go to all researchers attached to the laboratory of Mark Day for critical comments and helpful discussions. Our special thanks go to Dr Kenneth J Pienta, Professor, University of Michigan, for his support through the Rapid Autopsy Program and the SPORE affiliation. This work was supported by the National Institutes of Health (DK-056137) (MLD) and by the Specialised Programme in Research Excellence in Prostate Cancer (P50 CA69568) (MAR).

\section{REFERENCES}

Banks RE, Porter WH, Whelan P, Smith PH, Selby PJ (1995) Soluble forms of the adhesion molecule E-cadherin in urine. J Clin Pathol 48: 179-180 Bringuier PP, Umbas R, Schaafsma HE, Karthaus HF, Debruyne FM, Schalken JA (1993) Decreased E-cadherin immunoreactivity correlates with poor survival in patients with bladder tumours. Cancer Res 53: $3241-3245$

Cagiannos I, Karakiewicz P, Eastham JA, Ohori M, Rabbani F, Gerigk C, Reuter V, Graefen M, Hammerer PG, Erbersdobler A, Huland $H$, 
Kupelian P, Klein E, Quinn DI, Henshall SM, Grygiel JJ, Sutherland RL, Stricker PD, Morash CG, Scardino PT, Kattan MW (2003) A preoperative nomogram identifying decreased risk of positive pelvic lymph nodes in patients with prostate cancer. J Urol 170: $1798-1803$

Chan AO, Chu KM, Lam SK, Wong BC, Kwok KF, Law S, Ko S, Hui WM, Yueng YH, Wong J (2003) Soluble E-cadherin is an independent pretherapeutic factor for long-term survival in gastric cancer. J Clin Oncol 15: $2288-2293$

Chan AO, Lam SK, Chu KM, Lam CM, Kwok E, Leung SY, Yuen ST, Law SY, Hui WM, Lai KC, Wong CY, Hu HC, Lai CL, Wong J (2001) Soluble E-cadherin is a valid prognostic marker in gastric carcinoma. Gut 48: $808-811$

Coman D (1944) Decreased mutual adhesiveness, a property of cells from squamous cell carcinomas. Cancer Res 4: 625-629

Giroldi LA, Schalken JA (1993) Decreased expression of the intercellular adhesion molecule E-cadherin in prostate cancer: biological significance and clinical implications. Cancer Metast Rev 12: 29-37

Gofuku J, Shiozaki H, Doki Y, Inoue M, Hirao M, Fukuchi N, Monden M (1998) Characterization of soluble E-cadherin as a disease marker in gastric cancer patients. Br J Cancer 78: $1095-1101$

Griffiths TR, Brotherick I, Bishop RI, White MD, McKenna DM, Horne CH, Shenton BK, Neal DE, Mellon JK (1996) Cell adhesion molecules in bladder cancer: soluble serum E-cadherin correlates with predictors of recurrence. Br J Cancer 74: 579-584

Hara M, Koyanagi Y, Inoue T, Fukuyama T (1971) Some physico-chemical characteristics of '-seminoprotein', an antigenic component specific for human seminal plasma. Forensic immunological study of body fluids and secretion. VII. Nippon Hoigaku Zasshi 25: $322-324$

Katayama M, Hirai S, Kamihagi K, Nakagawa K, Yasumoto M, Kato I (1994a) Soluble E-cadherin fragments increased in circulation of cancer patients. Br J Cancer 69: $580-585$

Katayama M, Hirai S, Kamihagi K, Nakagawa K, Yasumoto M, Kato I (1994b) Soluble E-cadherin fragments increased in circulation of cancer patients. Br J Cancer 69: 580-585

Kattan MW, Eastham JA, Stapleton AM, Wheeler TM, Scardino PT (1998) A preoperative nomogram for disease recurrence following radical prostatectomy for prostate cancer. J Natl Cancer Inst 90: 766-771

Kattan MW, Potters L, Blasko JC, Beyer DC, Fearn P, Cavanagh W, Leibel S, Scardino PT (2001) Pretreatment nomogram for predicting freedom from recurrence after permanent prostate brachytherapy in prostate cancer. Urology 58: 393-399

Kuefer R, Hofer MD, Gschwend JE, Pienta KJ, Sanda MG, Chinnaiyan AM, Rubin MA, Day ML (2003) The role of an $80 \mathrm{kDa}$ fragment of E-cadherin in the metastatic progression of prostate cancer. Clin Cancer Res 9: $6447-6452$

Noe V, Fingleton B, Jacobs K, Crawford HC, Vermeulen S, Steelant W, Bruyneel E, Matrisian LM, Mareel M (2001) Release of an invasion promoter E-cadherin fragment by matrilysin and stromelysin-1. J Cell Sci 114: $111-118$

Partin AW, Carter HB, Chan DW, Epstein JI, Oesterling JE, Rock RC, Weber JP, Walsh PC (1990) Prostate specific antigen in the staging of localised prostate cancer: influence of tumour differentiation, tumour volume and benign hyperplasia. J Urol 143: 747-752

Partin AW, Kattan MW, Subong EN, Walsh PC, Wojno KJ, Oesterling JE, Scardino PT, Pearson JD (1997) Combination of prostate-specific antigen, clinical stage, and Gleason score to predict pathological stage of localised prostate cancer. A multi-institutional update. JAMA 277: $1445-1451$
Potter SR, Horniger W, Tinzl M, Bartsch G, Partin AW (2001) Age, prostate-specific antigen, and digital rectal examination as determinants of the probability of having prostate cancer. Urology 57: 1100-1104

Pound CR, Partin AW, Eisenberger MA, Chan DW, Pearson JD, Walsh PC (1999) Natural history of progression after PSA elevation following radical prostatectomy [see comments]. JAMA 281: 1591-1597

Protheroe AS, Banks RE, Mzimba M, Porter WH, Southgate J, Singh PN, Bosomworth M, Harnden P, Smith PH, Whelan P, Selby PJ (1999) Urinary concentrations of the soluble adhesion molecule E-cadherin and total protein in patients with bladder cancer. Br J Cancer 80: $273-278$

Rashid MG, Sanda MG, Vallorosi CJ, Rios-Doria J, Rubin MA, Day ML (2001) Posttranslational truncation and inactivation of human Ecadherin distinguishes prostate cancer from matched normal prostate. Cancer Res 61: 489-492

Rhodes DR, Sanda MG, Otte AP, Chinnaiyan AM, Rubin MA (2003) Multiplex biomarker approach for determining risk of prostate-specific antigen-defined recurrence of prostate cancer. J Natl Cancer Inst 95(9): $661-668$

Rios-Doria J, Day KC, Kuefer R, Rashid MG, Chinnaiyan AM, Rubin MA, Day ML (2002) The role of Calpain in the proteolytic cleavage of E-cadherin in prostate and mammary epithelial cells. J Biol Chem 278(2): $1372-1379$

Rubin MA, Mucci NR, Figurski J, Fecko A, Pienta KJ, Day ML (2001) Ecadherin expression in prostate cancer: a broad survey using highdensity tissue microarray technology. Hum Pathol 32: 690-697

Ryniers F, Stove C, Goethals M, Brackenier L, Noe V, Bracke M, Vandekerckhove J, Mareel M, Bruyneel E (2002) Plasmin produces an e-cadherin fragment that stimulates cancer cell incasion. Biol Chem 383: $159-165$

Sands ME, Zagars GK, Pollack A, von-Eschenbach AC (1994) Serum prostate-specific antigen, clinical stage, pathologic grade, and the incidence of nodal metastases in prostate cancer. Urology 44: 215-220

Syrigos KN, Krausz T, Waxman J, Pandha H, Rowlinson-Busza G, Verne J, Epenetos AA, Pignatelli M (1995) E-cadherin expression in bladder cancer using formalin-fixed, paraffin-embedded tissues: correlation with histopathological grade, tumour stage and survival. Int J Cancer 64: $367-370$

Takeichi M (1988) The cadherins: cell - cell adhesion molecules controlling animal morphogenesis. Development 102: 639-655

Takeichi M (1990) Cadherins: a molecular family important in selective cell-cell adhesion. Annu Rev Biochem 59: 237-252

Takeichi M (1993) Cadherins in cancer: implications for invasion and metastasis. Curr Opin Cell Biol 5: 806-811

Umbas R, Schalken JA, Aalders TW, Carter BS, Karthaus HF, Schaafsma HE, Debruyne FM, Isaacs WB (1992) Expression of the cellular adhesion molecule E-cadherin is reduced or absent in high-grade prostate cancer. Cancer Res 52: 5104-5109

Velikova G, Banks RE, Gearing A, Hemingway I, Forbes MA, Preston SR, Hall NR, Jones M, Wyatt J, Miller K, Ward U, Al-Maskatti J, Singh SM, Finan PJ, Ambrose NS, Primrose JN, Selby PJ (1998) Serum concentrations of soluble adhesion molecules in patients with colorectal cancer. Br J Cancer 77: 1857 - 1863

Wang MC, Valenzuela LA, Murphy GP, Chu TM (1979) Purification of a human prostate specific antigen. Invest Urol 17: 159-163

Wheelock MJ, Buck CA, Bechtol KB, Damsky CH (1987) Soluble 80-kd fragment of cell-CAM 120/80 disrupts cell-cell adhesion. J Cell Biochem 34: $187-202$ 